\title{
CONTROLE JUDICIAL DO ATO ADMINISTRATIVO AMBIENTAL
}

\section{JUDICIAL CONTROL OF ENVIRONMENTAL ADMINISTRATIVE ACT}

\section{Adriano Garcia de Souza ${ }^{1}$, Luís Antônio Borges ${ }^{2}$, José Luiz Pereira de Rezende ${ }^{3}$}

${ }^{1}$ Advogado. Mestre em Ciências Florestais pela Universidade Federal de Lavras. Chefe do Escritório Regional IBAMA Lavras/MG. E-mail: garcia22@gmail.com ${ }^{2}$ Prof. Adjunto UFLA. Departamento de Ciências Florestais. Setor de Conservação da Natureza.luis.borges@dcf.ufla.br

${ }^{3}$ Prof. Titular UFLA. Departamento de Ciências Florestais. Setor de Manejo Florestal.jlprezen@dcf.ufla.br

\begin{abstract}
RESUMO
Este trabalho visa avaliar o controle judicial atual dos atos administrativos ambientais, considerando a evolução da doutrina jurídica pós Constituição Federal de 1988, cuja concepção vem, paulatinamente, sendo alterada a partir de então. A inserção, no texto constitucional, de princípios norteadores da administração pública, aliada aos mandamentos específicos da tutela ambiental, vem levando os estudiosos do direito a modificarem a visão tradicionalista do princípio da presunção de legalidade do ato administrativo, quando este puder causar significativo dano ambiental à biodiversidade. Tal posicionamento da doutrina jurídica tem levado alguns tribunais a apreciarem, com maior rigor, os princípios norteadores do ato administrativo ambiental, analisando não só seus aspectos formais, mas também sua motivação, razoabilidade, proporcionalidade e finalidade. Entretanto, a defesa dos doutrinadores do direito administrativo na ampliação do controle judicial do ato administrativo ambiental, não vem se traduzindo em uma sensível alteração na jurisprudência, que ainda reflete um posicionamento dos tribunais na análise exclusiva da parte formal do processo. O controle judicial ampliado, apesar de ainda não ser uma regra na análise judicial dos atos administrativos ambientais, demonstra um caminho a ser alcançado na preservação dos recursos ambientais, ampliando os mecanismos de controle hoje existentes.
\end{abstract}

Palavras-chave: Legislação ambiental. Processo administrativo. Controle judicial.

\begin{abstract}
This work evaluated the current judicial control of the environmental administrative acts, considering the evolution of the legal doctrine after the Federal Constitution of 1988. The legal conception of the environmental administrative act has, gradually, being modified after the promulgation of the Federal Constitution of 1988. The insertion, in the constitutional text, of directional principles of the public administration, together with specific commandments of the environmental protection, forced the law scholars to modify the traditionalistic vision of the principle of the presumption of legality of the administrative act, when it is able to cause significant
\end{abstract}


environmental damage to biodiversity. Such positioning of the legal doctrine has forced some courts to judge, more severely, the principles of the environmental administrative act, analyzing not only the formal aspects of its establishment, but also its motivation, reasonableness proportionality and purpose. However, the defense of the doctrines of the administrative law in the amplification of the judicial control of the environmental administrative act is not causing a sensible alteration in the jurisprudence that still reflects a positioning of the courts in the exclusive analysis of its formulation. The extended judicial control, although not yet a rule in the judicial analysis of the environmental administrative acts, demonstrates a way to be pursued in the preservation of the natural resources, amplifying and diversifying the existing control mechanisms.

Keywords: Environmental legislation. Administrative proceeding. Judicial control.

\section{INTRODUÇÃO}

O Brasil vive uma nova realidade jurídica, na qual os atos administrativos envolvidos com a questão ambiental são constantemente levados ao controle do Poder Judiciário. Entretanto, tal realidade não indica uma situação de maior proteção ambiental, pois o sentimento privatista, que sempre prevaleceu na legislação, ainda norteia grande parte das decisões dos tribunais.

$\mathrm{Na}$ concepção tradicional da teoria do ato administrativo, ao Poder Judiciário cabe apenas o controle formal do ato, respeitando os limites da discricionariedade administrativa assegurados por lei. Tal concepção após a promulgação da Constituição Federal de 1988 vem sofrendo uma evolução significativa, onde os doutrinadores modernos entendem que os princípios constitucionais inseridos no caput do art. 37 alteraram a competência do poder judiciário no que concerne a avaliação dos atos administrativos que interferem diretamente na qualidade do meio ambiente.

No mesmo sentido, têm-se os princípios do direito administrativo, em especial o princípio da legalidade e da livre iniciativa, que se desenvolveram alicerçados em idéias opostas e necessárias, tendo de um lado a proteção aos direitos individuais frente ao estado e, de outro, a necessidade da garantia dos interesses coletivos.

Verifica-se, assim, que a análise jurídica do ato administrativo instaurado, visando à autorização para a utilização dos recursos ambientais, é essencial para a garantia do cumprimento dos princípios constitucionais da tutela ambiental e do direito administrativo, buscando conceder ao administrado e à coletividade a segurança imposta pela legislação vigente.

A complexidade do procedimento administrativo para a emissão de atos administrativos ambientais autorizativos, considerando a legislação ambiental e administrativa e a necessidade da apresentação de estudos técnicos e avaliação dos mesmos pelo órgão ambiental competente, merece especial atenção do administrador público.

Detecta-se a carência de doutrina específica sobre procedimento administrativo ambiental, que traz aspectos distintos do procedimento administrativo geral, por conter, além de exigências taxativas de documentação e atividades, um viés técnico que vincula o órgão ambiental, alterando a feição discricionária concedida à administração pública.

Este trabalho tem como objetivo avaliar o controle atual judicial dos atos administrativos ambientais considerando a evolução da doutrina jurídica pós Constituição Federal de 1988.

\section{HISTÓRICO DO CONTROLE JUDICIAL DOS ATOS ADMINISTRATIVOS "ESTADO DA ARTE"}

No Brasil, o direito administrativo não nasceu como ramo autônomo do direito, pois estava sob o regime da monarquia absoluta. Com o império, segundo Di Pietro (2001), já existia uma 
administração pública organizada, regida pelo direito privado, que o Conselho do Estado se limitava a aplicar. A partir dessa época começou a se desenvolver o direito administrativo, com grande influência do direito francês e italiano, e a surgir os primeiros doutrinadores que defendiam a autonomia da disciplina.

Meirelles (1995) afirmou que, ao conquistar sua autonomia, o direito administrativo sofreu redução em seu objeto, pois a matéria referente à política administrativa, que envolve estudos sobre a utilidade e conveniência de atuação do Estado na ordem social, foi delegada à ciência da administração. Dessa forma, o direito administrativo tem como objeto as matérias de natureza jurídica e tem sua formação doutrinária realizada de forma sistemática e específica, definindo de forma clara seus institutos e princípios informativos.

Vários são os critérios utilizados pelos doutrinadores para definir o direito administrativo, entre eles o do serviço público, poder executivo, relações jurídicas, negativo ou residual, distinção entre atividade jurídica e social do estado e da administração pública. Na visão tradicional do direito administrativo, Di Pietro (2001), definiu o ato administrativo:

"a declaração do Estado ou de quem o represente, que produz efeitos jurídicos imediatos, com a observância da lei, sob regime jurídico de direito público e sujeita a controle pelo Poder Judiciário."

Existem alguns princípios que norteiam o processo administrativo. Alguns são comuns ao processo judicial, como são o da publicidade, o da ampla defesa, o do contraditório, o do impulso oficial e o da obediência à forma e aos procedimentos estabelecidos em lei (MACHADO, 2004). Tais princípios diferenciam o ato administrativo do ato de direito privado, que são:

1. Princípio da legalidade

Teve sua origem no Estado de Direito e constituiu o principal instrumento da garantia dos direitos individuais. Ao estabelecer os direitos da administração pública, a lei também estabelece seus limites de atuação, determinando, de forma objetiva, até que ponto o poder público pode restringir o exercício dos direitos individuais em benefício da coletividade. Verifica-se, então, que a vontade da administração pública sempre é aquela que decorre da expressamente disposta em lei.

Isso implica dizer que, de acordo com o princípio da legalidade, a administração pública só pode fazer o que a lei permite, ao contrário do princípio da autonomia da vontade, aplicável às relações particulares, que permite fazer tudo que a lei não proíbe.

2. Princípio da supremacia do interesse público

Presente tanto na elaboração da lei como no momento de sua execução, tal princípio determina a finalidade dos atos públicos. A supremacia do interesse público reside na imperatividade da lei e na aplicação do imperativo constitucional de defesa ao meio ambiente, que não é de aplicação volitiva ou mesmo opcional, mas de aplicação cogente na salvaguarda ambiental.

\section{Princípio da impessoalidade}

Inserido no texto constitucional, este princípio determina que a administração pública não deva realizar sua atividade administrativa visando beneficiar ou prejudicar pessoas determinadas ou grupo de pessoas, pois deve sempre ter em vista o interesse público. Visualiza-se também que tal princípio norteia a publicidade das ações dos diversos órgãos da administração pública, uma vez que as realizações de obras e serviços não são do agente e sim da entidade administrativa que representa. 


\section{Princípio do controle ou tutela e autotutela}

Visa assegurar o cumprimento dos princípios norteadores do direito administrativo por todo o conjunto da administração pública. Confronta a regra geral da autonomia dos entes públicos, garantindo ao Estado, o direito de assegurar ao administrado que todos os atos públicos cumpriram as determinações emanadas da lei.

É um importante princípio do direito administrativo, que dá poderes ao Estado de fiscalizar todos os atos realizados pela administração publica direta, indireta e fundacional.

Registra-se que tal poder não pode ser presumido, pois deve ser exercido dentro dos limites definidos em lei.

\section{Princípio da Publicidade}

Tal princípio garante que o administrado receba dos órgãos públicos informações de seu interesse particular ou de interesse coletivo, sempre ressalvados os sigilos assegurados por lei. Verifica-se que a aplicação deste princípio é fonte permanente de acompanhamento social dos atos da administração pública, garantindo à sociedade civil organizada ou aos administrados, isoladamente, buscar junto ao Poder Judiciário, quando necessário, o controle da legalidade de tais atos.

A atuação da administração de forma contrária aos princípios citados, portanto, acarreta ao ato a invalidade dos efeitos almejados, e os atos subsequentes não deverão produzir efeitos válidos (ROSA, 2002). $\mathrm{Na}$ análise do processo judicial, alguns atributos associados ao princípio da legalidade, merecem destaque, por ser objeto da análise do ato administrativo quanto à sua validade. Estes atributos são:

- Presunção de legitimidade e veracidade. Atributo que garante ao ato administrativo, até que se prove o contrário, o estrito cumprimento do respeito à conformidade com a lei e a veracidade dos fatos alegados pela administração pública;

- Autoexecutoriedade. Atributo que garante ao ato administrativo sua execução imediata, sem intervenção do Poder Judiciário.

A inversão destes atributos na análise atual do ato administrativo ambiental propiciou a nova concepção jurídica da análise do referido ato.

\section{O ATO ADMINISTRATIVO AMBIENTAL PÓS-CONSTITUIÇÃO FEDERAL DE 1988}

No campo do direito ambiental, o ato administrativo ambiental é um instrumento de controle prévio, em que a administração verifica a regularidade do exercício de atividades controladas (SILVA, 1997). Dessa forma, cabe ao poder público analisar discricionariamente, segundo os critérios de conveniência e oportunidade, a solicitação para remover ou não a proibição do exercício da atividade pretendida (MILARÉ, 2004).

A teoria tradicional, na visão de Machado (1999), não contempla as mudanças doutrinárias ocorridas na concepção jurídica do ato administrativo ambiental. Tais mudanças refletem os princípios da legalidade, impessoalidade, moralidade, publicidade e eficiência, insertos na Constituição Federal de 1988 (art. 37, caput), os princípios informadores do direito ambiental, bem como os mandamentos constitucionais de preservação e conservação dos recursos ambientais (art. 225).

Os princípios informadores do direito ambiental, tal como consolidado pela Constituição Federal de 1988, devem ser considerados pela autoridade administrativa no momento da edição do ato administrativo ambiental. Dentre eles, merecem menção: 
1. Princípio do ambiente ecologicamente equilibrado como direito fundamental da pessoa humana Expresso no caput do artigo 225 da Constituição Federal de 1988 tem como escopo complementar os direitos e deveres individuais elencados no artigo $5^{\circ}$ do mesmo diploma legal (BRASIL, 1998). Trata-se, portanto de um novo direito fundamental da pessoa humana, que visa garantir condições adequadas à sobrevivência, vivendo em um ambiente saudável ou, nos termos da constituição, ecologicamente equilibrado. Traduz-se como uma extensão do direito à vida que, para Milaré (2004), deve ser visto sob o enfoque da própria existência física e saúde dos seres humanos e quanto ao aspecto da dignidade dessa existência, que faz com que valha a pena viver.

A inserção de tal princípio no texto constitucional passou a nortear toda aplicação e edição de normas jurídicas de grau inferior, adotando-se um enfoque que favoreça a aplicação das normas existentes no sentido de garantir a existência de um ambiente ecologicamente equilibrado. Antunes (2005) afirmou que se trata de um dos mais importantes princípios que norteiam a aplicação do direito ambiental.

\section{Princípio do controle do poluidor pelo Poder Público}

Trata-se do controle do poder público nas ações de manutenção, preservação e restauração dos recursos ambientais, princípio embasado no disposto em leis ordinárias e na Constituição Federal de 1988.

Segundo Mukai (2002) impõe-se ao poder público, em suas ações oriundas do poder de polícia administrativa, a fiscalização da utilização dos recursos ambientais de forma racional, que permita uma disponibilidade para a presente e as futuras gerações. Tal princípio permite também que os órgãos públicos estabeleçam termos de ajustamento de conduta (TAC) que propiciem a adequação de atividades antrópicas que degradam o meio ambiente, a fatores tecnicamente aceitáveis e, até mesmo, no dizer de Milaré (2004), a imposição de cessação de atividades nocivas.

3. Princípio da consideração da variável ambiental no processo decisório de políticas de desenvolvimento

Princípio que impõe a obrigação de se levar em conta a variável ambiental na tomada de decisões que impliquem na alteração negativa do meio ambiente. Machado (2004) afirma que este princípio impõe tal dever tanto para o Poder Público como para a iniciativa privada. Tem sua previsão no texto constitucional e vem sendo sistematicamente regulamentado pela legislação infraconstitucional.

Percebe-se que a crescente demanda de utilização dos recursos ambientais impõe a existência de uma política pública que faça com que todos os entes da administração tenham como princípio norteador, na implantação de obras, serviços e outras atividades, a preocupação com a preservação ambiental. A transversalidade da questão ambiental tem como objetivo principal a prevenção e a mitigação de impactos negativos e a otimização dos impactos positivos.

\section{Princípio da participação comunitária}

Princípio que não é exclusivo do direito ambiental e expressa a imposição da participação da comunidade nos processos de gestão das questões ambientais. Leva em conta que a participação comunitária na resolução das questões ambientais é condição necessária para a efetivação de um processo de gestão ambiental confiável e permanente.

Machado (2004) defende que a participação do cidadão nas tomadas de decisão pressupõe uma política ambiental séria e responsável, que contribua de forma efetiva para a minoração dos impactos ambientais negativos e incremento dos impactos considerados positivos.

Ressalta-se que o direito à participação, na afirmativa de Mukai (2002), pressupõe o direito à informação, o que possibilita uma melhor articulação da sociedade com o poder público, na busca da implementação de uma política ambiental que favoreça a manutenção da qualidade do ambiente natural. 
Acima de tudo, a aplicação prática de tal princípio permite a descentralização do processo decisório e divide as responsabilidades, fazendo com que todos os atores envolvidos tenham consciência e responsabilidade na fiscalização das atividades que, de alguma forma, degradem o meio ambiente, permitindo um maior controle da política ambiental.

\section{Princípio da prevenção}

Princípio que se refere à necessidade de se prevenir contra ações que possam degradar o meio ambiente. Tal princípio, no dizer de Machado (2004), se baseia no entendimento de que os conhecimentos técnicos existentes podem contribuir para a melhoria da qualidade ambiental e devem ser empregados na execução de atividades que, sob qualquer forma, possam causar degradação ambiental. Alguns autores, como Machado (2004) e Derani (1997), preferem qualificálo como princípio da precaução, afirmando que, no caso de incerteza científica sobre a natureza dos impactos causados, deve-se impedir o desenvolvimento da atividade, até que seja demonstrada sua segurança ambiental.

\section{Princípio da função socioambiental da propriedade}

Segundo Carvalho (1999), antes da Constituição Federal de 1988, o Código Civil Brasileiro de 1916 ostentava uma concepção de intocabilidade da propriedade particular, na qual, salvo algumas exceções expressas em lei, principalmente no que se referia ao direito de vizinhança, o proprietário detinha todo o poder de uso, gozo e fruição da propriedade, sem se preocupar com os impactos negativos que pudesse causar ao meio ambiente.

A nova realidade instalada no Brasil, com a promulgação da Constituição Federal de 1988, modificou o conceito privatista do direito de propriedade, socializando-o, inserindo a necessidade de que tal direito só poderá ser exercido na sua plenitude, desde que as necessidades coletivas sejam observadas no uso, gozo e fruição da propriedade. Tal conceito não implica dizer que a propriedade deixou de ser privada, mas sim de que ela deve cumprir sua função social na comunidade.

O legislador brasileiro, atento às mudanças introduzidas pela Constituição Federal de 1988, aprovou a Lei $\mathrm{n}^{0}$ 9.784, de 29 de janeiro de 1999, que regula o processo administrativo no âmbito da administração pública federal, ampliando os princípios constitucionais citados, inserindo, entre outros, os princípios da finalidade, motivação, razoabilidade e proporcionalidade (art. $2^{\circ}$ ).

A alteração legal citada consolidou a evolução conceitual do ato administrativo ambiental, possibilitando, segundo a doutrina dominante, ao Poder Judiciário excluir o princípio da presunção de legitimidade e veracidade do ato administrativo ambiental passível de provocar dano ambiental significativo, cabendo ao Poder Público o ônus de demonstrar a legitimidade e veracidade do ato editado.

Apesar da evolução doutrinária, Krell (2004) afirmou que, no controle dos atos administrativos ambientais:
"a tão criticada abstenção ou timidez dos tribunais no controle dos atos administrativos dificilmente tem acontecido. Muito pelo contrário: inúmeras pessoas ou empresas, detentoras de elevado poder econômico e político, já conseguiram que a justiça liberasse os seus projetos de legalidade mais do que duvidosa (v.g.: loteamentos e construções irregulares). Especialmente nos julgados dos Tribunais de Justiça Estaduais existe uma nítida tendência de relegar os aspectos de proteção ambiental para um segundo plano."

Ocorre que aspectos sociais e políticos, tais como movimentos da sociedade civil organizada e implementação de políticas públicas de conservação dos recursos ambientais, estão mudando a 
realidade jurídica no país, fazendo com que cada vez mais o rigor na análise dos requisitos legais que norteiam o procedimento administrativo ambiental seja submetido à apreciação do Poder Judiciário.

Constata-se uma mudança gradual e crescente na realidade jurídica brasileira, em que, segundo a doutrina majoritária, a crescente utilização do instituto da ação civil pública tem permitido ao Poder Judiciário ultrapassar sua competência de somente corrigir erros de avaliação dos órgãos administrativos, para chegar, até mesmo, a identificar os valores sociais do ato contestado.

Krell (2004) se reporta a Ackel Filho (1990), que afirmou o seguinte:

"no âmbito da ação civil pública, também chamada de ideológica, a discricionariedade não constitui óbice para a decisão jurisdicional no caso de obrigação de fazer ou não fazer, fundada em interesse do bem comum, porque a definição do que seja este não é exclusiva do Executivo, mas objetivo fundamental da República e seus Poderes."

Percebe-se, na visão da moderna doutrina jurídica, que quando o órgão ambiental competente autoriza a implantação de um empreendimento efetiva ou potencialmente poluidor, interpretando a legislação ambiental sob uma ótica específica, que não a do Ministério Público ou organização da sociedade civil ou de qualquer cidadão, terá o Poder Judiciário, ao ser acionado, de verificar, além das formalidades legais do ato administrativo, se a administração realmente interpretou de forma correta a norma material, independente do poder discricionário conferido à administração pública nestes casos.

Para melhor elucidar a matéria, Krell (2004), assim se manifestou:

"este tipo de ato administrativo (licença/autorização ambiental) normalmente envolve juizo discricionário dos órgãos ambientais, visto que as leis costumam empregar conceitos indeterminados de natureza técnica, valorativa e/ou de prognose. Mesmo assim, o juiz não está restrito a um controle formal ou uma revisão na base dos princípios constitucionais. É esta a fundamental diferença para o controle a ser efetuado no âmbito do mandado de segurança ou da ação civil comum (ações não ideológicas), onde o Judiciário deve conceder a preferência ou prerrogativa de avaliação para os órgãos administrativos competentes."

$\mathrm{Na}$ esteira das transformações, algumas decisões dos tribunais já acompanham a moderna doutrina, avaliando não só a formação do ato administrativo ambiental como também os seus princípios formadores, interferindo diretamente na discricionariedade concedida à administração pública.

Apesar de tímida, a absorção, pelos julgadores, da moderna concepção jurídica do ato administrativo ambiental vem crescendo, tendo alguns julgados considerados como de mérito a análise dos princípios norteadores da administração pública. Dentre eles, destaca-se o voto proferido pelo Desembargador Federal Souza Prudente reconhecendo a importância da avaliação destes princípios como norteadores da tutela ambiental. $\mathrm{O}$ acórdão disse o seguinte: 
2000.34.00.023222-7/DF; APELAÇÃO CIVEL, DESEMBARGADOR FEDERAL SOUZA PRUDENTE SEXTA TURMA

20/08/2007 DJ p.80

$02 / 04 / 2007$

A Turma, à unanimidade, negou provimento à apelação.

CONSTITUCIONAL E ADMINISTRATIVO. AÇÃO POPULAR. DEPARTAMENTO NACIONAL DE PRODUÇÃO MINERAL - DNPM. GUIA DE UTILIZAÇÃO. ARTS. $5^{\circ}$ E $6^{\circ}$ DA INSTRUÇÃO NORMATIVA $N^{\circ} .1 / 2000$. LESÃO AO MEIO AMBIENTE. INSTITUTO BRASILEIRO DO MEIO AMBIENTE E DOS RECURSOS AMBIENTAIS RENOVÁVEIS - IBAMA. I - A aferição da existência ou não de ilegalidade do ato, bem como, do potencial, ou efetivo, caráter lesivo ao patrimônio público, à moralidade administrativa, ao meio ambiente e ao patrimônio histórico e cultural, que dele decorre, constitui o próprio mérito da ação popular, autorizando-se, pois, o manejo desse instrumento processual, objetivando a anulação de instrução normativa, que possibilita a extração de substância mineral sem o prévio licenciamento ambiental, amparada em suposta ilegalidade e potencialidade danosa do ato ao meio ambiente.

II - Em questão ambiental, como no caso, deve-se privilegiar, sempre, o princípio da precaução, já consagrado em nosso ordenamento jurídico, inclusive com status de regra de direito internacional, ao ser incluido na Declaração do Rio, como resultado da Conferência das Nações Unidas sobre Meio Ambiente e Desenvolvimento - Rio/92, como determina o seu Princípio 15, nestas letras: "-Com a finalidade de proteger o meio ambiente, os Estados devem aplicar amplamente o critério da precaução, conforme suas capacidades. Quando houver perigo de dano grave ou irreversivel, a falta de uma certeza absoluta não deverá ser utilizada para postergar-se a adoção de medidas eficazes para prevenir a degradação ambiental."

III - A imprescindibilidade de prévio licenciamento ambiental para emissão, por parte do Departamento Nacional de Produção Mineral, de qualquer autorização para extração de substância mineral, afigura-se, em princípio, amparada pela tutela cautelar constitucionalmente prevista no art. $225, \S 1^{\circ}$, $V$ e respectivo $\S 3^{\circ}$, da Constituição Federal, na linha auto-aplicável de imposição ao poder público e à coletividade o dever de defender e preservar o meio ambiente ecologicamente equilibrado, como bem de uso comum do povo e essencial à sadia qualidade de vida, para as presentes e gerações futuras (CF, art. 225, caput).

IV - Apelação desprovida.

No mesmo sentido, tem-se o voto proferido pelo Ministro Herman Benjamin in verbis:

RECURSO ESPECIAL N 938.484 - MG (2007/0070337-2)

RELATOR: MINISTRO HERMAN BENJAMIN

RECORRENTE: ESTADO DE MINAS GERAIS

PROCURADOR: CÉSAR RAIMUNDO DA CUNHA E OUTRO(S)

RECORRENTE: CENTRAIS ELÉTRICAS DA MANTIQUEIRA S/A - CEM ADVOGADO: WERNER GRAU NETO E OUTRO(S) 
RECORRIDO: MINISTÉRIO PÚBLICO DO ESTADO DE MINAS GERAIS EMENTA PROCESSUAL CIVIL E AMBIENTAL. VIOLAÇÃO DO ART. 535 DO CPC. DEFICIÊNCIA NA FUNDAMENTAÇÃO. SÚMULA 284/STF. AUSÊNCIA DE PREQUESTIONAMENTO. SÚMULA 211/STJ. ALÍNEA "C". NÃO-DEMONSTRAÇÃO DA DIVERGÊNCIA.

1. Cuidam os autos de Ação Civil Pública ajuizada pelo Ministério Público contra Centrais Elétricas da Mantiqueira - CEM e o Estado de Minas Gerais, com o fito de evitar danos ambientais com a pretendida construção $e$ instalação de Pequena Central Hidrelétrica - PCH em Área de Preservação Permanente. O Juízo de $1^{o}$ grau julgou procedente o pedido, tendo sido confirmada a sentença pelo Tribunal de Justiça.

2. Não se conhece de Recurso Especial em relação à ofensa ao art. 535 do CPC quando a parte não aponta, de forma clara, o vício em que teria incorrido o acórdão impugnado. Aplicação, por analogia, da Súmula 284/STF.

3. Os dispositivos legais tidos por violados (arts. 10 e 17-L da Lei 6.938/1981) carecem de prequestionamento, porquanto não houve manifestação sobre as normas neles contidas, a despeito da oposição de Embargos de Declaração. Incidência da Súmula 211/STJ.

4. Nem mesmo de forma implícita a questão está prequestionada, tendo em vista que o Tribunal de origem não cuidou da competência administrativa para a concessão de licenciamento. Seu julgamento baseou-se estritamente no art. 225 da Constituição e no potencial dano ambiental demonstrado nos autos, reforçado pela constatação de que o custo social é superior ao interesse lucrativo individual buscado com o empreendimento, o qual não integra o sistema interligado de energia elétrica.

5. O acórdão recorrido encontra-se em sintonia com a tendência atual da doutrina e da jurisprudência, que reconhece a possibilidade de controle judicial da legalidade "ampla" dos atos administrativos. Como muito bem decidido pelo Tribunal, "em se tratando de direitos da terceira geração, envolvendo interesses difusos e coletivos, como ocorre com afetação negativa do meio ambiente, o controle deve ser da legalidade ampla", ou seja, se o ato administrativo (no caso o licenciamento ambiental) afronta o sistema jurídico, seus valores fundamentais e seus princípios basilares "não podem prevalecer".

6. A divergência jurisprudencial deve ser comprovada, cabendo a quem recorre demonstrar as circunstâncias que identificam ou assemelham os casos confrontados, com indicação da similitude fática e jurídica entre eles. Indispensável a transcrição de trechos do relatório e do voto dos acórdãos recorrido e paradigma, realizando-se o cotejo analítico entre ambos, com o intuito de bem caracterizar a interpretação legal divergente. O desrespeito a esses requisitos legais e regimentais (art. 541, parágrafo único, do CPC e art. 255 do RI/STJ) impede o conhecimento do Recurso Especial, com base na alínea " $c$ " do inciso III do art. 105 da Constituição Federal.

7. Recursos Especiais não conhecidos.

ACÓRDÃO

Vistos, relatados e discutidos os autos em que são partes as acima indicadas, acordam os Ministros da Segunda Turma do Superior Tribunal de Justiça: "A Turma, por unanimidade, não conheceu dos recursos, nos termos do voto 
do(a) Sr(a). Ministro(a)-Relator(a)." Os Srs. Ministros Mauro Campbell Marques, Eliana Calmon, Castro Meira e Humberto Martins votaram com o Senhor Ministro Relator. Dr.(a). WERNER GRAU NETO, pela parte RECORRENTE: CENTRAIS ELÉTRICAS DA MANTIQUEIRA S/A - CEM Brasília, 08 de setembro de 2009 (data do julgamento).

Esta decisão demonstra que a posição majoritária dos doutrinadores vem, aos poucos, sendo absorvida pelos tribunais, proporcionando um avanço significativo no processo judicial de revisão dos atos administrativos ambientais. Ainda no mesmo sentido, tem-se visto a tendência de uma evolução dos tribunais em afirmar que não há restrição ao poder revisional dos mesmos sobre o juízo da Administração, quando esta não reconhece os valores da vida.

Tal assertiva reproduz na prática a evolução conceitual do ato administrativo ambiental, proclamada pelos doutrinadores, demonstrando que o Poder Judiciário, cada vez mais, deve se valer de seu poder revisional, para coibir que princípios norteadores do direito administrativo, em especial os formadores do ato administrativo ambiental, sejam relegados a um plano inferior, com vistas a privilegiar o interesse de particulares em detrimento dos interesses da coletividade.

\section{CONCLUSÕES}

O processo administrativo ambiental, formador do ato administrativo ambiental, possui características próprias que o difere do processo administrativo comum, apesar de manter as características marcantes da discricionariedade da administração pública, vincula suas decisões aos estudos técnicos ambientais apresentados, garantindo a consideração dos princípios norteadores do procedimento administrativo e do direito ambiental.

Verifica-se que o administrador público deve obrigatoriamente analisar o cumprimento de todas as condições impostas por lei, além da análise e manifestação sobre o fiel cumprimento dos princípios garantidores da proteção ambiental em favor de toda a coletividade.

O controle do ato administrativo ambiental, exercido pelo Poder Judiciário, ultrapassa os limites do controle do processo administrativo comum, por ser considerado um processo em que interesses difusos são objetos de deliberação. O controle judicial amplo do ato administrativo ambiental deve ser considerado mais um importante instrumento em defesa dos recursos ambientais.

O administrador público deve cumprir rigorosamente os ditames legais, quando da emissão do ato administrativo ambiental, observando tanto os aspectos administrativos e técnicos, sob pena do ato que originou a autorização ser considerado nulo por autoridade superior ou mesmo pelo Poder Judiciário, nos termos da moderna concepção jurídica, que valoriza os princípios do direito como meio de dar efetividade a tutela dos recursos ambientais.

\section{REFERÊNCIAS}

ANTUNES, P. de B. Direito ambiental. 7. ed. rev. e atual. Rio de Janeiro: Lúmen Júris, 2005. $1126 \mathrm{p}$.

BRASIL. Constituição da República Federativa do Brasil. 18. ed. atual. e ampl. São Paulo: Saraiva, 1998. 291 p. (Coleção Saraiva de Legislação).

CARVALHO, C. G. de. Legislação ambiental brasileira. Leme: ed. de Direito, v. 1, 1999, 1121 p. 
DERANI, C. Direito ambiental econômico. São Paulo: Max Limonad, 1997.

DI PIETRO, M.S.Z. Direito administrativo. 13. ed. São Paulo: Atlas, 2001. 674 p.

KRELL, A.J. Discricionariedade administrativa e proteção ambiental: o controle dos conceitos jurídicos indeterminados e a competência dos órgãos ambientais: um estudo comparativo. Porto Alegre: Livraria do Advogado, 2004. 151 p.

MACHADO, P.A.L. Direito ambiental brasileiro. 12. ed. Rev. Atual e Ampl. São Paulo: Malheiros, 2004. 1064 p.

MACHADO, P.A.L. Direito Ambiental Internacional e Biodiversidade. Revista Cej Centro de Estudos Judiciários da Justiça Federal, BRASILIA, p. 156-158, 1999. Disponível em: www2.cjf.jus.br/ojs2/index.php/cej/aticle/viewarticle/223/385 Acesso em: 04 set. 2009.

MEIRELLES, H.L. Direito administrativo brasileiro. 20. ed. atual. São Paulo: Malheiros, 1995. $734 \mathrm{p}$.

MILARÉ, É. Direito do meio ambiente: doutrina, prática, jurisprudência, glossário. São Paulo: Revista dos Tribunais, 2004. 1024 p.

MUKAI, T. Direito ambiental sistematizado. São Paulo: Saraiva, 2002. 214 p.

ROSA, M.F.E. Direito administrativo. 3. ed. São Paulo: Saraiva, 2002. 231 p.

SILVA, J.A. da. Direito ambiental constitucional. 2. ed. São Paulo: Malheiros, 1997. 306 p.

Manuscrito recebido em: 26/04/2010 Revisado e Aceito em: 18/04/2012 